\title{
GENERAL PRACTITIONER TRAINING IN THE ARMY
}

\author{
Major J. G. WALLER, M.B., D.T.M. \& H., R.A.M.C.* \\ Dr. JOHN FRY, M.D., F.R.C.S. \\ Honorary Consultant in General Practice to the Army
}

\begin{abstract}
Introduction
IN accordance with the change in outlook on general practice in the R.A.M.C., and the idea of selecting and training some more senior non-specialist officers as "Chiefs of Army Group General Practice ", one of us (J.G.W.) attended such a course in 1964. This article attempts to describe some of the highlights of the course and to comment on future requirements for the continued education of Army general practitioners.
\end{abstract}

\section{Variety of Material}

Following an initial period at Beckenham for briefing, discussion and study of the principles of general practice organization, a further four general practice units were visited.

There was Dr. R. G. Gibson's old-established group at Winchester, where one stayed at the fine, modern Officers' Mess of the Green Jackets Depot. Here one must not be surprised to be provided with a suite of modern bedroom furniture, with both a study and fully-fitted private bathroom adjoining! The opportunity should also be taken of seeing some of the architecture of the old town, especially the College with its beautifully designed War Memorial. In marked contrast was Harlow New Town--a fantrstic lump of concrete with the practice groups organized by Lord Taylor housed in theis modern, specially-built premises. Further examples of practice were seen with Drs. W. Morgan Evans and G. S. Adams, both situated in the Middlesex suburbs and with a wealth of outside appointments, but differing in their internal organization. At some of these locations, one also had the chance of visiting colleagues with still other types of practice and premises. Further valuable knowledge of practice layout and organization was gained from Dr. G. S. Adams in his capacity of Director, General Practice Advisory Service-an indication of future trends in National Health Service practice.

Apart from visits to medical officers of health and local authority clinics, interesting outside appointments included industrial units (Firestone Tyre Factory, B.O.A.C. London Airport, Poyle Industrial Health Service) and rehabilitation centres, schools for physically handicapped children, spastic day units, an audiometry centre and even a geriatric clinic.

As a change from general practice, a few hospital departments were included in the programme, the subjects-paediatrics, dermatology, E.N.T. and psychiatry-being appropriately chosen.

A day was spent with Dr. D. L. Crombie of Birmingham, who is Honorary Director, College of General Practitioners Records and Statistical Advisory Unit. This visit afforded an opportunity of studying practice records from the point of view of observational research.

Another day was spent with Drs. John and Valerie Graves of Chelmsford; on the important theme of post-graduate education. This wonderful couple have not only 
pioneered tape-recording of medical subjects but are particularly interested in teaching by group discussion. This is referred to below.

Finally, there was the University of Edinburgh General Practice Teaching Unit under Professor Richard Scott, where methods of under-graduate teaching can be studied and ideas on post-graduate education formulated.

\section{Outline of subjects covered in the course}

1. Scope of general practice. Very similar in civil and military practice with the exception of geriatrics (in the main) and possibly obstetrics.

2. Practice planning. Both civil and military practices are faced with a manpower shortage and hence the need for organization-probably into groups of 4 to 6 doctors.

3. Premises. Good accommodation is needed for these groups. The opportunity of seeing plans and layouts is afforded particularly at Harlow, Ashford and Edinburgh.

4. Staff. The receptionist and secretary fill an important role, as they make the first contact with the patient-yet they are recruited untrained. Both civil and military have this problem at present, though the new Association of Medical Secretaries may in time change the outlook in civil practice.

Trained staff whose functions were studied included health visitors, nurses, midwives and social workers, and in several practices one or more of these ancillary workers are now attached permanently. In the Army these functions are combined by the S.S.A.F.A. sister.

5. Special clinics. Ante-natal and child welfare clinics were held on the practice premises at most of the locations visited.

6. Equipment. Some useful items of medical and office equipment were noted.

7. Appointment systems. These were seen in operation in most practices. Their success in the Army would depend on availability of transport. We should also attempt to do more on our own premises, without resort to hospital referral.

8. Records. Medical record cards for military families should be brought into use, and interchange of records between the National Health Service and Army facilitated. Why not use Standard National Health Service envelopes and cards? Records for administrative, statistical and research purposes are covered at most locations and particularly at Birmingham.

9. Observational research can easily be based on the above records.

10. Relations with colleagues. Professional meetings.

11. Relations with Hospitals. Essential for the modern general practitioner.

12. Postgraduate education. These last three items are linked together and discussed under "continued education".

\section{Conclusions}

The requirements of good general practice are best summed up in Lord Taylor's own words:

"In itself, good management does not produce good doctoring, but it makes good doctoring much easier. Practice management can easily be overdone. Over-organization results in mechanical efficiency but the loss of personal and family interest in the patient. Under-organization results in industrial fatigue for the doctor. The happy medium 
relieves the doctor of what can be properly done by others less skilled than himself. The keys to good organization are practice-planning, proper accommodation and the proper use of ancillary help".

We consider that the present course covers these requirements on the civil side, and most of the material is equally applicable to military practice.

Difficuity only arises at present when selecting officers of different experience for this course. Some have had more civil experience than others, while those with less military experience might require guidance on, for example, supply problems. In time, thése problems will be overcome, as officers will automatically have had experience in our own military general practices.

A similar course or a modification would also be suitable as a refresher for medical officers who have been in Army practice for some time, or who wish to become acquainted with trends in National Health Service practice.

\section{Future trends in continued education}

The idea implied in "continued education" is that it takes place all the time the doctor is working (in his Group Practice) and is much more vital than "courses". An important function of the Chief of the Group Practice would be to organise continued education in his Group. The following measures are applicable:-

1. Meetings. The general practitioners get together for group discussion. This involves a small group of people of equivalent status meeting deliberately to discuss a previously agreed subject and to learn from one another. Each member in turn might take charge of the meeting in an unobtrusive way. Advantages of such discussion: groups are:-

(a) Bring persons together.

(b) The general practitioner hears of new advances and ideas.

(c) Subject matter-the general practitioner by nature reads journals and attends courses on subjects that interest him. It is important to fill the gaps in his knowledge of other subjects. General practitioners have to keep up with all the subjects and we are inclined to concentrate on the ones we like best.

(d) Discussion groups can and do convert people to regular reading again.

(e) Minimum of organization, travel and expense.

$(f)$ A continuing process of gradual assimilation (c.f. intense concentration of courses).

The great value of recorded talks is that they provide a ready-made starting point for discussion. This avoids the difficulty of finding a speaker, and people can argue and criticise without embarrassment. A talk can be produced with great care for a particular need, made by the best speakers (recorded as if talking to small groups, not as a lecture)rehearsed, polished and illustrated with diagrams and photographs ( $2 \times 2$ slides). A reel of tape is small and light for posting all over the world.

2. Partial specialisation. Each doctor to take up a particular subject as a "speciality", for example, ENT, paediatrics. This is becoming necessary because the whole range of medical knowledge is so vast. In this way he would have a chance of keeping upto-date in his subject instead of trying to cover the whole field.

$\mathrm{He}$ would be available for consultation by other members of the Group. 
Also, at the meetings, each member could take his turn to speak on his own subject and keep the others up-to-date.

3. Hospitals. There is no doubt that the general practitioner of the future must be part of a hospital and be treated as a member of the staff. In spite of the above possibilities, the only real way to keep up-to-date is by regular (daily) contact with a hospital.

A plan going rather further, and one which should not be too difficult to organize in the R.A.M.C., is periodic exchange between general practitioners and hospital doctors, for short periods. The general practitioner would be able to see the more serious cases coming from outside and the application of the latest therapeutic advances. Moreover, he would be in the hospital atmosphere, attend conferences, see pathological techniques, and generally bring his ideas up-to-date. The specialist would benefit by broadening his practice experience, as well as re-learning how to make a diagnosis with his ears, eyes and hands.

Such exchanges would be especially beneficial in the case of a medical officer who had been stationed for a time too far from a hospital.

We consider that the R.A.M.C. might show a lead in these aspects of continued education.

\section{Acknowledgements}

We are indebted to all the civilian doctors who acted as tutors on the course, for their valuable help and advice and particularly to Drs. John and Valerie Graves and Dr. Constance Gibbs of Edinburgh for the benefit of their advice on post-graduate education.

\section{REFERENCE}

Graves, V. (1964). Postgrad. med. Journ. 40, 1-3.

\section{Honorary Consultant}

Doctor George H. Newns, M.D., F.R.C.P., has been appointed Honorary Consultant in Paediatrics to the Army in succession to Doctor Philip R. Evans, M.Sc., M.D., F.R.C.P., who has retired.

Dr. Newns is Physician at the Hospital for Sick Children, Great Ormond Street.

\section{Royal Society of Medicine}

At a meeting on July 19th, Sir Arthur Porritt was elected President in succession to Lord Cohen of Birkenhead.

Colonel J. M. Matheson, O.B.E., M.D., M.R.C.P., F.R.C.S., Professor of Military Surgery, R.A.M. College, has been elected a Member of Council of the Clinical Section of The Royal Society of Medicine. 